\title{
Os reveses do ensino de História Antiga no Brasil
}

\author{
Los reveses de la enseñanza de Historia Antigua en Brasil \\ The setbacks of teaching Ancient History in Brazil
}

\author{
Juliana Porto Machado ${ }^{1}$ \\ Ronaldo Bernardino Colvero ${ }^{2}$ \\ Letícia Ferreira Porto ${ }^{3}$
}

\begin{abstract}
Resumo
O presente artigo tem como objetivo principal refletir acerca da nova BNCC e suas consequências para a História Antiga, considerando o papel do livro didático como material de auxílio do professor e discorrendo também, sobre a pesquisa e o ensino na área de História Antiga no Brasil. Ressaltando a importância da produção científica nesse campo do conhecimento para questionar e perceber a alteridade e diversidade cultural.
\end{abstract}

Palavras-Chave: História Antiga; BNCC; livro didático; pesquisa; ensino.

\section{Resumen}

El presente artículo tiene como objetivo principal reflexionar acerca de la nueva BNCC y sus consecuencias para la Historia Antigua, considerando el papel del libro didáctico como material de ayuda del profesor y discurriendo también, sobre la investigación y la enseñanza en el área de Historia Antigua en Brasil. Resaltando la importancia de la producción científica en ese campo del conocimiento para cuestionar y percibir la alteridad y diversidad cultural.

Palabras-Clave: Historia Antigua; BNCC; libro de texto; la investigación; educación.

\begin{abstract}
The main objective of this article is to reflect on the new BNCC and its consequences for Ancient History, considering the role of the didactic book as a teacher aid material and also discussing research and teaching in the area of Ancient History in Brazil. Emphasizing the importance of scientific production in this field of knowledge to question and perceive otherness and cultural diversity.
\end{abstract}

Keywords: Ancient History; BNCC; textbook; search; teaching.

\footnotetext{
${ }^{1}$ Mestre e Doutoranda em Memória Social e Patrimônio Cultural pela Universidade Federal de Pelotas, pósgraduanda em Ensino de História pela Universidade Federal do Pampa; contato: julianamachado209@gmail.com

${ }^{2}$ Doutor em História pela Pontifícia Universidade Católica do Rio Grande do Sul. Professor adjunto na Universidade Federal do Pampa (São Borja) - Professor do Pós-Graduação de Políticas Públicas da Universidade Federal do Pampa e do Pós-Graduação em Memória Social e Patrimônio da Universidade Federal de Pelotas. Contato: rbcolvero@gmail.com

${ }^{3}$ Licenciada em pedagogia pela Universidade Federal de Pelotas (UFPEL)- Contato: Tita_krica@ hotmail.com
} 


\section{Introdução}

A história antiga estimula a compreensão da alteridade histórica, possibilitando entender as estruturações das formações de outras sociedades que se diferenciam da qual estamos inseridas, exercitando uma visão de mundo crítica e reflexiva de si e do outro, do pensar e do agir em sociedade. Pois, a "consciência formada historicamente olha para o passado e é capaz de reconhecer a especificidade do tempo presente, é capaz de reconhecer o seu lugar no presente, tendo como referência o passado. E desenvolver uma competência interpretativa do passado e do presente" (SILVA; WEISS, 2015; p 03). Assim, o ensino pautado na multiculturalidade supera a ideia de identidades homogêneas, fator que irá influenciar diretamente na formação crítica dos estudantes.

Dessa forma, mediante as resoluções da nova BNCC (Base Nacional Comum Curricular) deve se pautar o direito que o jovem estudante possui de compartilhar os saberes, as experiências, o reconhecimento do Outro, da pluralidade cultural e a história da produção humana. Assume-se que é impossível abarcar todos o saber da humanidade, e todas as civilizações, porém é inigualável a necessidade de ao menos ser trabalhado em sala de aula os marcos históricos universais, base essencial na construção da visão crítica da sociedade.

Assim, de acordo com Gonçalves e Silva (2008) os livros de didático, devido aos seus problemas, apresentam o estudo da antiguidade sem enfoque na alteridade; sendo que para os autores a investigação e transmissão da Antiguidade apresenta uma ampla dimensão para a compreensão e ensino da pluralidade cultural. Sendo que, os livros de didáticos estão centrados em simplificações, generalizações e anacronismos, em que a história antiga parte sempre da visão eurocêntrica, uma única cultura.

Nesse sentido, a História antiga é um campo que está inserido na História geral, e por isso acaba em ambiente escolar sendo trabalhada sem o devido aprofundamento e reflexões de fatos históricos. Em vista disso, este artigo tem como objetivo refletir acerca da nova BNCC e suas consequências para a História Antiga, considerando o papel do livro didático como material de auxílio do professor e discorrendo também, sobre a pesquisa e o ensino na área de História Antiga no Brasil, apontando assim a importância e necessidade da investigação de História antiga em território brasileiro. Esta discussão será baseada em revisão bibliográfica de textos explorados em aula durante a disciplina História Antiga e Ensino a História ${ }^{4}$ e textos complementares.

\footnotetext{
${ }^{4}$ Disciplina da Especialização em Ensino de História.
} 


\section{História antiga em sala de aula: os impactos da nova BNCC e o papel do livro didático}

Para discutir os impactos da BNCC no ensino de História partiremos da conceituação da Base Nacional Comum, que segundo as Diretrizes Curriculares Nacionais Gerais para a Educação Básica (DCN/EB) e a Lei de Diretrizes e Bases da Educação Nacional (LDB/1996) apresenta-se como:

Os conhecimentos, saberes e valores produzidos culturalmente, expressos nas políticas públicas e que são gerados nas instituições produtoras do conhecimento científico e tecnológico; no mundo do trabalho; no desenvolvimento das linguagens; nas atividades desportivas e corporais; na produção artística; nas formas diversas de exercício da cidadania; nos movimentos sociais (BRASIL, Parecer CNE/CEB n ${ }^{\circ}$ 07/2010, p. 31).

Compreendendo que a BNCC é a uma política curricular projetada para uniformizar os currículos das escolas da Educação Básica do país, uma ferramenta que tem como objetivo principal moldar o conhecimento e padronizar, para possibilitar uma coesão sociocultural, respondendo a uma lógica de mercado de reflexões fragmentadas e rápidas, do útil e do imediatismo para atividades profissionais, em que não haja espaço para propostas de mudanças e inovações do meio. Uma vez que, de acordo com Macedo (2014) não é a estipulação de currículo comum que irá fazer com que a educação tenha qualidade, esse nada mais é que uma ferramenta de tentativa de domínio hegemônico.

De acordo com Couto (2014) a definição da BNCC apresenta um arcabouço tradicionalista, autoritarista e ideológico de saberes impostos a uma ideia de comum a todos. Com isso, para Mello (2014; p.23) a Base Comum "mantém a lógica da prescrição diretiva, que não se agrega às atuações efetivas para investimento no professor e em sua autonomia profissional e curricular, nem vincula-se a iniciativas concretas de melhoria das condições de trabalho docente", considerando que o ambiente escolar e o trabalho do professor e sua autonomia de transmissão não são contemplados pela BNCC.

Nesse sentido, ainda Mello (2014) argumenta que a Base impossibilita um contato e percepção da bagagem cultural do aluno na realização de troca efetivas com o professor, visto que a "autonomia docente estará circunscrita à escolha do método, ou seja, do como irá ensinar o conteúdo a ser examinado, e menos na compreensão dos contextos das escolas e das situações de vida dos alunos"(p.24).

Já no tocante a História Antiga, de acordo com Silva (2010) essa é uma disciplina essencial para fomentar discussões entorno da formação das identidades sociais. Vale destacar que na nova BNCC os conteúdos de história antiga e medievo são apresentados aos alunos no ensino fundamental, para o autor esse fato é preocupante devido a não retomada de tais 
conteúdos no ensino médio, porque sem o devido aprofundamento dos assuntos podem ser produzidos e legitimados certos estereótipos como exemplo da superioridade da História clássica. Além do fato da apresentação da História em uma linearidade explicada em: Mesopotâmia, ensino do Egito, Grécia, Roma, cristianismo, queda do império romano, medievo, antiguidade e no ensino médio a História do Brasil, África e Américas.

Porém, um dos pontos mais preocupantes da BNCC de 2015 foi a quase exclusão de conteúdos da antiguidade da disciplina de história, para Coelho e Belchior (2017) isso ocorreu primeiramente pela história antiga ser considerada distante em sua temporalidade da realidade atual do país, dificultando na compreensão e no estabelecimento de ligação entre as culturas. Assim, como o desconhecimento de línguas como o latim, grego, alemão e o inglês, que dificultam o acesso a fontes voltadas para estudos das antiguidades clássica. Considera-se também que a ausência da História Antiga esteja relacionada a localização geográfica do Brasil e o distanciamento dessa em relação a países do nicho clássico como Roma e Grécia, elemento que pode afetar em possíveis pesquisas e investimentos para tais.

Dessa forma, ressalta-se que a proposta da BNCC está partindo de uma estruturação que tem a história do Brasil como centro em que se estabelece a partir dessa, ligação com outras culturas do passado, no entanto, em relação a Pré-História, História Antiga e Medievo há dificuldades na concretização dessas associações com o contexto nacional, como apontou os autores precitados. Nesse modelo da Base Nacional Comum, buscou-se um afastamento do conhecimento a partir da visão eurocêntrica, tendo a formação multicultural do Brasil como cerne.

Sem embargo, as transformações no campo educacional propostas pela BNCC impossibilitarão aos estudantes um aprofundamento crítico acerca da antiguidade histórica, como exemplo na compreensão da própria Política nacional já que no Brasil a consolidação da área política está calcada na formação de um vocábulo de origem greco-romano e nas leis romanas, além disso a História Antiga é uma constante na memória social do país seja na literatura, na arquitetura e outros nichos. Com isso, sem a abordar a antiguidade corresse o perigo da formação de alunos incapazes de refletirem criticamente sobre a esfera social, cultural, econômica e política, ou seja, a sociedade em que está inserido caso a História Antiga não seja discutida em contexto escolar. Como aponta Cami (p.04):

a História escolar como um simples processo de transmissão de conteúdos factuais e verbalistas. Tradição esta que estimula crianças e jovens a tomarem o passado como dado, ao invés de serem instigados a se perguntar como nós sabemos sobre o passado e de serem preparados para formular perguntas e elaborar respostas cada vez mais complexas acerca dele. 
Dessa maneira, a efetivação de uma base curricular comum principalmente no que tange ao saber histórico em espaço escolar ocasiona questionamento de meio social, como o que deve ser ensinado do passado para os estudantes? No qual há uma seleção de memórias relevantes a serem rememoradas e outras que são esquecidas. Como argumenta Ricoeur (2007) a memória tem como múnus a lembrança, em um ato de coerção subjetiva a nós, em um laço emocional e social do direito que o outro possui de não ser esquecido. Em um movimento de compartilhamento que não recordamos apenas as representações de nós mesmos, mas de nossas relações de vivência com o mundo e os saberes, das experiências com o outro e com o contexto, com isso a História é mecanismo de rememoração.

E por isso, deve se perceber que ao estabelecer compartilhamentos comuns de conhecimentos a serem ensinado ocorre a eliminação de memórias em uma classificação de importante e não importante. Nesse processo de escolhas deve ser considerar que de fato não há como abarcar tudo em alguns semestres e períodos de aula, porém não se deve descartar a História dos antigos povos, uma história plural, uma vez que essa é fulcral para compreender e reconhecer a multiculturalidade do país, os valores estabelecidos e a alteridade.

Logo, outro ponto de relevância a ser discutido é a utilização de material de base para auxiliar o professor em sala de aula, mais especificamente do uso do livro didático muitas vezes como o único apoio distribuído nas escolas. Sendo que, o livro deve ser considerado como um produto mercadológico com vida útil reduzida, uma vez que a indústria editorial é um mercado em constante produção. Em vista disso, os livros apresentam uma estruturação baseada em anacronismo ${ }^{5}$ e informações decodificadas em que os fatos históricos são apresentados sistematicamente em uma linearidade de processos contínuos, em que são classificadas as histórias em ordem hierarquia de primitivas à evoluídas (WEISS; SILVA, 2015).

No entanto, para Barnabé (2014) cumprem a função de apresentar uma linguagem de acesso possível ao universo cientifico, em que existe uma transformação da linguagem acadêmica para o ambiente escolar, por meio de exercícios baseados em perguntas e respostas, em soluções de problemas e dicas de trabalhos em grupos, considerando alguns valores, ideologias de certas sociedades. $\mathrm{O}$ autor trabalha com as instâncias formadoras de parâmetros que condicionam o tempo de utilização da obra, considerando o Estado, a opinião

\footnotetext{
${ }^{5} \mathrm{O}$ anacronismo apresenta-se como o uso de conceito e ideias de uma época para analisar os fatos de outro tempo.
} 
pública, as instituições escolares, e a editora, dessa forma como um produto social está no meio de discussões de espaço público.

Especificamente em relação a história antiga, partes do senso comum da apresentação das antigas civilizações compartilhando um mesmo universo cultural, em um olhar provido no presente na busca da interpretação dos valores do passado. Um olhar pautado na superficialidade que ocasiona a formação de reflexões estereotipadas que contribuíram com o etnocentrismo.

Como ressaltam Weiss e Silva (2015) os profissionais que trabalham na criação de obras didáticas demonstram dificuldades em trabalhar com a alteridade e o multiculturalismo, atribuindo concepções desatualizadas sobre diversos conceitos como o de classes, da continuidade histórica e do tempo em uma linha retilínea. Esse produto padronizado é distribuído no ambiente escolar, de fato existem obras completas com reflexões de especialistas das áreas, porém essas obras não são de acesso das escolas públicas. Assim:

\begin{abstract}
Algumas obras mantêm uma abordagem tradicional da História Antiga, que em alguns momentos compromete por não acompanhar inovações dos debates da academia, enquanto que outras, em detalhes pontuais, avançam em reflexões que problematizam as sociedades antigas para além de esquemas simplificadores estanques, interna e externamente. Respectivamente abordam: a política, a sociedade, a economia, a cultura, a religião, dissociadas; as relações entre povos não são abordadas. O conceito de simultaneidade entre os povos é suprimido em detrimento do movimento de ascensão e queda [...] (BARNABÉ, 2014).
\end{abstract}

Nessa acepção o livro didático apresenta-se como um objeto auxiliar do professor em sala de aula, o mesmo apresenta em si, conforme Barnabé (2014) pouca mudança, essas só ocorrem efetivamente em resposta as demandas do mercado editorial. Em outra perspectiva, pode-se constatar que apesar das fragmentações, desatualizações e anacronismo do livro didático ele é ainda base funcional em sala de aula, através dele é possível o professor estabelecer um olhar crítico aos discursos e desconstruir a linearidade apresentada junto com o aluno que pode exercitar seu olhar questionador, mas como aponta Gonçalves e Silva (2001) isso depende da formação do professor.

Para o autor precitado, o livro didático apresenta muitas deficiências principalmente em suas simplificações ${ }^{6}$, porém advoga que se o professor estiver reorientado e capacitado para uma visão crítica o livro será uma importante fonte educacional. Os autores ainda apontam que a escola não é reconhecida como um ambiente de produção de conhecimento, e sim como reprodutora de saberes constituídos em outros espaços científicos, influenciando na

\footnotetext{
${ }^{6} \mathrm{O}$ autor se refere-se a uma distorção dos fatos históricos.
} 
defasagem dos conteúdos, ao estabelecimento do distanciamento entre escola e meio acadêmico.

\section{A pesquisa e o ensino de História Antiga}

No Brasil a investigação entorno da História Antiga surge concomitantemente com a disciplina de História no ambiente acadêmico. Sendo em 1940 o surgimento da primeira oferta de História Antiga na Universidade de São Paulo, fato de certa forma recente, logo, a produção de material voltado para esse campo de pesquisa tem aumento significativo no século XXI, o meio universitário como propulsor da difusão de pesquisas dessa área (SILVA, 2001). Pois, como aponta Morales (2017; p.82) "pesquisadores de História Antiga normalmente estão alocados em faculdades ou departamentos de História”.

Destaca-se que essa projeção de produção estava fortemente enraizada, inicialmente, ao contexto do Brasil da época, com a eclosão da ditadura militar. Assim, a História Antiga caminha para o campo da curiosidade, e até mesmo do exotismo, em que se conhece o diferente, para Funari (2007) esse tipo de pensamento carrega a História antiga a ser transmitida como uma antiguidade maniqueísta sem espaço para o aprofundamento das estruturações dos processos históricos.

Torna-se fulcral percebermos que o objetivo que se tinha para com a investigação dos clássicos, no Brasil, era apenas em uma visão elitizada, contribuindo para a moralidade e ética na formação dos sujeitos, por meio da base erudita europeia. Excluindo neste modelo a ideia de diversidade cultural. $\mathrm{O}$ autor aponta que essa forma de ensino era particularmente voltada para os sujeitos de classe alta. Em um cenário contemporâneo a História antiga, no âmbito escolar, está dissolvida em meio a disciplina de História geral, como já mencionado, em que há uma condensação dos conteúdos em que todos os processos acabam sendo narrados como similares, em uma mesma categoria sociocultural.

Silva (2001) argumenta que há um aumento considerável na produção cientifica acerca de temáticas relacionadas ao estudo da História antiga, porém apesar desse importante passo os estudantes que adentram o meio universitário em cursos de história estão cheios indagações sobre a cultura (saber/fazer) das antigas civilizações, apresentam apenas uma visão homogênea da antiguidade em um fluxo reto, que não possibilita um olhar plural. Assim, utilizar fontes históricas e métodos de investigação em espaço de aprendizagem, é, deverás um mecanismo de aprofundamento para entender o hibridismo e a existência do etnocentrismo. Uma vez que, como Geertz (2008) aponta a cultura não é algo fácil de ser 
interpretada como uma história já escrita, ao contrário, se faz complexa devido aos fatos sociais e às mudanças de contexto.

O ser humano atribui significado ao seu universo em um processo de criação de signos e símbolos, que cabe ao pesquisador reinterpretá-lo em dados descritivos, em um processo de discriminação detalhada o mais próximo possível do estilo de viver de determinado grupo (INGOLD, 2008), percebendo a interação do outro com o seu espaçotempo frente às trivialidades do cotidiano, como reagem a fatos diversos e a sua visão de mundo, sendo papel da História investigar e transmitir o mundo simbólico em sociedades do passado no presente . Como indica Silva (2001, p. 05) “devemos buscar compreender o passado por ele mesmo e o presente como resultado de transformações".

Em meio as indagações do passado, vale destacar como advogam Weiss e Silva (2015) a problemática existente da separação que ocorre entre pesquisa e ensino, que provoca uma hierarquização em que a pesquisa está em um cenário acima do ensino. Esse tipo de perspectiva deve ser desfeito, uma vez que, pesquisa e ensino devem ser colocadas em um processo de colaboração na formação do aluno e professor, na produção e transmissão do conhecimento e na construção da consciência histórica.

Temos na História Antiga um campo amplo de investigação que permite trabalhar com o auxílio de outras ciências como a arqueologia, sociologia, antropologia e filosofia. Dessarte para Funari e Garraffoni (2004) a História Antiga deve ser trabalhada com o uso de fontes provindas de outras áreas do conhecimento. Ferramentas essenciais para uma visão pormenorizada dos conteúdos e assim, como indica a PCN (Plano Curricular Nacional) de estudos transversais um acesso livre a discussões pertinentes sobre hibridismo, pluralidade, multiculturalismo, memórias coletivas e individuais, identidades heterogêneas, gênero, modos de vidas, política, patrimônio nacional em suas múltiplas vertentes, induzindo a uma visão de certa maneira despida de preconceitos já estabelecidos em relação as outras sociedades. E assim, afirma Francisco (2017, p.54) “a História Antiga nos apresenta uma possibilidade ímpar de observação crítica de esquemas de identidade e memória, e o cenário amplo de crítica é, em certa medida, responsável por isso". Logo, os temas transversais contribuem para um entendimento do passado através de uma visão crítica e embasada em evidências históricas. Tornando a intepretação do passado em um processo contínuo de renovação das imagens desse no presente (SILVA, 2010).

É necessário que não haja um estranhamento por parte do transmissor (autor) na abordagem do passado e dos estudos da história antiga, mas que demonstre em sua exposição 
dos fatos uma visão que facilite a compreensão do distanciamento cultural existente entre os contextos, porém acima de tudo buscando o entendimento de que o outro do passado também faz parte da humanidade (WEISS; SILVA, 2015). Dessa forma, é essencial perceber que a pesquisa e o ensino são interelacionados, que não deve haver uma separação antagônica dos métodos de investigação e aprendizado. Como afirmaram os autores precitados a produção de material cientifico no campo da História Antiga no Brasil está em um crescente, fato que resulta na necessidade da transmissão de fatos históricos da antiguidade.

\section{Considerações Finais}

A análise e reflexão crítica do passado é fator fundamental para a percepção de asserções contemporâneas como os preconceitos estabelecidos, as hierarquias de poder, o etnocentrismo, a desigualdade econômica, religiosidades, identidades, memórias, esquecimento e outros, o ensino de História Antiga possibilita essas análises e aprofundamentos dos fatos do passado e do presente, principalmente no que tange o reconhecimento da diversidade cultura.

Dessa forma, como trabalhado neste artigo uma possível exclusão da História Antiga em sala de aula, seria uma perda inestimável. De toda maneira, a exposição da BNCC em um História Antiga que só é ensinada no fundamental, mais especificamente no sexto ano, sem os devidos debates e discussões acabam por seguir em uma produção contínua de estereótipos e de análises fragmentadas, em um constante anacronismo. Todavia, a História Antiga propicia um amplo conjunto de compartilhamento dos saberes e experiências da humanidade em sociedade, um universo plural, em que pode se estimular a desconstrução de histórias unas.

A própria rede de conexão que a História estabelece com outras ciências oportuniza múltiplas interpretações de um mesmo fato, em que diversas memórias serão identificadas em que as identidades esquecidas terão espaço. Como aponta Funari e Garrafoni (2004) "estudos das sociedades antigas trouxeram para cena as mulheres, os libertos ricos e pobres, os escravos, os bandidos, as prostituas, camponeses, os sujeitos que, até então, tinham sido amontoados sob o rótulo de povo ou excluídos dos discursos sobre o passado” (p.18).

O retorno ao antigo é uma forma de buscar compreender as estruturações do presente. Assim, a questão do livro didático pode ser analisada de duas maneiras, a primeira em que esse tipo de material está baseado em uma lógica comercial, reproduzindo modelos anacrônicos, desatualizados e fragmentado, em outro sentido apesar desses problemas existente, o livro ainda tem papel central em sala de aula, sendo muitas vezes o único material 
de consulta do professor, professor esse que muitas vezes é designado a ensinar disciplinas que não são de sua especialidade, nesse sentido tem no livro uma roteirização de transmissão do conteúdo.

Assim, esse modelo de aprendizagem está calcado a muito tempo nas escolas públicas, então a ruptura com essa forma mecanicista baseada em livros didáticos deve ser iniciada aos poucos, uma vez que é injusto colocar toda a carga de mudança nos ombros do professor de escola pública que podem refutar uma nova abordagem ao qual não possuem domínio. Para alguns especialistas a renovação no sistema de transmissão de conhecimento se dá a partir do ingresso de novos sujeitos com olhares mais positivos a transformação do ensino conservador do livro didático. Portanto, a situação do professor em ambiente escolar dever ser considerada quando se pensa em mudanças. Mas, em sala de aula a utilização de fontes e outros recursos tecnológicos podem auxiliar o professor em sua transmissão dos conteúdos. Por fim, as discussões entorno do ensino da História Antiga são extensas e complexas e devem ser consideradas a partir de múltiplas percepções.

\section{Referências}

BRASIL. Base Nacional Comum Curricular (BNCC). Consulta Pública. Brasília, MEC/CONSED/UNDIME, 2015. Disponível em: http://basenacionalcomum.mec.gov.br/wpcontent/uploads/2018/02/bncc-20dez-site.pdf Acesso em: 28 de setembro de 2018.

BARNABÉ, Luis Ernesto. De olho no presente: História Antiga e livros didáticos no século XXI.OPSIS, Catalão-GO, v. 14, n. 2, p. 114-132 - jul./dez. 2014

BELCHIOR, Ygor; SANTOS, Ana Lúcia Coelho. "A BNCC e a História Antiga: uma possível compreensão do presente pelo passado e do passado pelo presente", Mare Nostrum, n.8, 2017, pp. 62-78.

CAIMI, Flávia Eloisa. Base Nacional Comum Curricular. Parecer sobre o documento de História. 2015. Disponível em: <http://basenacionalcomum.mec.gov.br/\#/site/relatoriosanaliticos>. Acesso em: 02 de outubro de 2018.

COUTO, Lúcia Helena. Currículo como direito de aprendizagem: uma experiência nacional para o Ciclo de Alfabetização. 2014. 120 p. Dissertação (Mestrado em Educação). Pontifícia Universidade Católica de São Paulo, 2014. Disponível em: https://sapientia.pucsp.br/bitstream/handle/9817/1/Lucia\%20Helena\%20Couto.pdf Acesso em: 30 de setembro de 2018.

FRANCISCO, Gilberto da Silva. O lugar da História Antiga no Brasil. Mare Nostrum, n.8, 2017, pp. 30-61.

FUNARI, Pedro Paulo Abreu; GARRAFFONI, Renata Senna. História Antiga na Sala de Aula. Campinas, IFCH/UNICAMP, julho de 2004, Textos Didáticos n. 51, 90 pp. 
GONÇALVES, Ana Teresa; SILVA, Gilvan Ventura da. Algumas reflexões sobre os conteúdos de História Antiga nos livros didáticos brasileiros. História e Ensino, Londrina, v.7, p.123-141, 2001.

GEERTZ, Clifford. A Interpretação das Culturas. Rio de Janeiro: LTC, 2008.

GRÜNEWALD, Rodrigo de Azeredo. Horizontes Antropológicos. Porto Alegre, ano 9, nº 20 , p. 141-159, outubro de 2003.

INGOLD, T. Anthropology is not Ethnography. Proceedings of the British Academy, 154, 2008.

MACEDO, Elizabeth. Base Nacional Curricular Comum: novas formas de sociabilidade produzindo sentidos para educação. Revista e Curriculum. São Paulo, v. 12, n. 3, p.1530 1555, out./dez., 2014. Disponível em: http://revistas.pucsp.br/index.php/curriculum Acesso em: 02 out. 2018.

MELLO, Paulo Eduardo Dias de. Base Nacional Comum, Direitos e Objetivos de Aprendizagem e Desenvolvimento e o IDEB: nexos, contextos, rastros e o lugar do professor. Paraná UEPG/PR; $2014 . \quad$ Disponível em: file:///C:/Users/ju/Downloads/Base_Nacional_Comum_Direitos_e_Objetivos.pdf Acesso em: 30 de setembro de 2018.

MORALES, Fábio da Silva. Por uma didática da História Antiga no Ensino Superior. Mare Nostrum, n.8, 2017, pp. 79-114.

RICOEUR, Paul. A memória, a história, o esquecimento. Campinas, SP: Unicamp, 2007.

SILVA, Semíramis Corsi. Aspectos do ensino de história antiga no Brasil: algumas observações. Alétheia: Revista de estudos sobre Antigüidade e Medievo, 2010, v.1, p. 145-154

WEISS, Jussemar; DA SILVA, Lisiana. "O ensino de História Antiga: algumas reflexões". Anais do XVIII simpósio nacional de História - ANPUH, 2015. 15p 